\title{
Life Course Socioeconomic Conditions and Metabolic Syndrome in Adults: The Atherosclerosis Risk in Communities (ARIC) Study
}

\author{
Kristal L. Chichlowska, PhD, MPH, Kathryn M. Rose, PhD, Ana V. Diez-Roux, MD, PhD, \\ MPH, Sherita H. Golden, MD, MHS, Annie M. McNeill, PhD, and Gerardo Heiss, MD, PhD \\ From the Department of Epidemiology, School of Public Health, the University of North Carolina at \\ Chapel Hill, NC (K.L.C., K.M.R. and G.H.); the Department of Epidemiology, University of Michigan \\ School of Public Health, Ann Arbor, MI (A.V.D.-R.); Department of Medicine, Johns Hopkins \\ University School of Medicine, Baltimore, MD (S.H.G.); Merck and Co., North Wales, PA (A.M.M).
}

\begin{abstract}
Purpose-This study examined the effect of childhood, adulthood and cumulative SES (cumSES) on the prevalence of metabolic syndrome (MetS) in middle-aged adults in the Atherosclerosis Risk in Communities Study, (1987-89).
\end{abstract}

Methods-Participants included 2,461 black and 8,536 white men and women ages 45 to 64 years without diabetes. Socioeconomic status (SES) measures from childhood, early adulthood and mature adulthood were used to create a cumSES score. Childhood SES, early adult SES, mature adult SES and cumSES scores were grouped into two categories (high/low). Age- and center-adjusted prevalence ratios and 95\% confidence intervals for MetS, using 2005 ATP III criteria, by SES were estimated by log-linear regression for race-sex groups.

Results-Black and white women with low childhood SES, early adult SES, mature adult SES or cumSES were more likely to have the MetS than those with high SES. These associations remained after adjustment for physical activity, smoking status and drinking status. In contrast, there was no association of SES with MetS in men.

Conclusions-Our findings suggest that socioeconomic disadvantage early in life and across the life course influence risk of the MetS in black and white women.

\section{Keywords}

Socioeconomic Status; Life Course; Childhood; Metabolic Syndrome

\section{INTRODUCTION}

Almost a quarter of United States (US) adults are estimated to have the metabolic syndrome (MetS) (1,2). MetS (1), a condition defined as a cluster of risk factors including impaired insulin sensitivity, dyslipidemia, hypertension, and central adiposity, is associated with increased risk of diabetes, atherosclerosis, coronary heart disease (CHD), and cardiovascular disease (CVD)

(C) 2009 Elsevier Inc. All rights reserved.

Corresponding author: Kristal Chichlowska PhD, MPH, California Tribal Epidemiology Center, Address: 4400 Auburn Blvd., $2^{\text {nd }}$ Floor, Sacramento, CA 95842, Phone: 916-929-9761 Fax: 916-929-7246 kristal.chichlowska@crihb.net.

Publisher's Disclaimer: This is a PDF file of an unedited manuscript that has been accepted for publication. As a service to our customers we are providing this early version of the manuscript. The manuscript will undergo copyediting, typesetting, and review of the resulting proof before it is published in its final citable form. Please note that during the production process errors may be discovered which could affect the content, and all legal disclaimers that apply to the journal pertain. 
morbidity and mortality (2-6). Consistent inverse associations between socioeconomic status (SES) and the MetS in adults are observed (7-21). Some studies report lower childhood SES to be associated with an increased occurrence of the MetS in adulthood $(11,20)$, whereas others have not $(14,22)$. Many of these studies $(7-13,15,18-20)$ observed sex differences, with stronger SES - MetS associations among women.

The mechanisms by which SES may impact the MetS are largely unknown. Abdominal obesity and defects in insulin sensitivity are the two main drivers of the MetS (23-25). Hypothalamicpituitary-adrenocortical (HPA) axis dysfunction may contribute to the development of obesity and insulin resistance (26). Low SES may promote dysregulation of the HPA axis $(27,28)$, such that persons with low SES may experience more stressful life events than persons with higher SES and may be more vulnerable to the negative impacts of stress over time on health (28). SES may also influence the development of the MetS through behavioral CVD risk factors (29), living conditions (30), and access to health care (31).

While associations between specific life periods and the MetS have been reported $(11,12,14$, 20), the impact of the cumulative influence of socioeconomic circumstances during the life course on the MetS has yet to be investigated. We examined associations between childhood, early adulthood, middle adulthood and cumulative SES and the MetS in a middle-aged black and white cohort of men and women in the Atherosclerosis Risk in Communities (ARIC) Study. Additionally, we examined whether SES - MetS associations were mediated by behavioral CVD risk factors, and if their influence varied by life epoch. We hypothesized that the accumulation of exposures to low SES across the life course is associated with increased prevalence of the MetS in adulthood.

\section{METHODS}

\section{Study Population}

The ARIC study includes a community-based prospective cohort assembled to investigate the etiology and natural history of atherosclerosis and its sequelae. From 1987 to 1989, the ARIC study examined 15,792 black and white residents ages 45 to 64 years in four communities in North Carolina (NC), Mississippi (MS), Minnesota (MN), and Maryland (MD). Two communities (Washington County, MD and Minneapolis, MN suburbs) were mostly white. Blacks were over-sampled in Forsyth County, NC (12\% black) and exclusively sampled in Jackson, MS to provide sufficient power to investigate findings by race/ethnicity. A comparison of participants to non-respondents has been described (32). The Institutional Review Boards at the involved institutions approved the study, and all participants gave informed, written consent. A detailed description of the ARIC Study has been published (33).

In 2000-2001, as part of the ancillary Life Course Socioeconomic Status, Social Context and Cardiovascular Disease (LC-SES) Study, ARIC participants were administered a life course questionnaire during an annual follow-up (34). Participants were queried about their SES during childhood and early adulthood. The LC-SES Study included 12,716 of the baseline ARIC Study participants; the remaining 3076 ARIC Study participants were lost to follow up, deceased or refused to participate.

Of the 12,716 eligible participants, we excluded participants with diabetes $(n=1,201)$ or an unknown diabetes status $(\mathrm{n}=96)$, with missing data that precluded classification of any of the components of the MetS $(n=593)$, with a race other than black or white $(n=35)$ and black participants in Minneapolis, MN or Washington County, MD ( $\mathrm{n}=39)$. Type II diabetes was defined as a fasting blood glucose level greater than $126 \mathrm{mg} / \mathrm{dL}$, nonfasting blood glucose level greater than $200 \mathrm{mg} / \mathrm{dL}$, use of hypoglycemic medications or self-reported physician diagnosis. Our final sample size was 10,997. Compared to participants in the full ARIC Study cohort, 
participants that were excluded in our analysis were less likely to be current smokers, to have hypertension, and to be black, and were more likely to be current drinkers. As a result, the effect of life course SES and MetS may be underestimated.

\section{Ascertainment of Socioeconomic Status}

This cumulative SES (cumSES) score was created by summing the values for each of the four SES variables in each life epoch using methods previously described (35). Briefly, childhood SES measures included parental education at the time of birth $\left(<8^{\text {th }}\right.$ grade, $8^{\text {th }}$ grade, $>8^{\text {th }}$ grade), and parental occupation (manual, non-manual), parental occupational role (no managerial role, managerial role), and parental home ownership (rent home or other, own home) during childhood. SES variables used for young adulthood (age 30 years) were education ( $<$ high school, high school graduate, > high school), occupation (manual, non-manual), occupational role (no managerial role, managerial role), and home ownership (rent home or other, own home). SES variables used for older adulthood (age 45-64 years) were income (< $\$ 25,000, \$ 25,000-\$ 34,999, \geq \$ 35,000$ ), occupation (manual, non-manual), occupational role (no managerial role, managerial role), and home ownership (rent home or other, own home). Each life epoch (childhood, young adulthood, older adulthood) was assigned a score ranging from of 0 to 5 . Each life epoch score was summed to create the cumSES score. Thus, the cumSES scores ranged from $0(0+0+0)$ to $15(5+5+5)$, with higher values of the cumSES score indicative of higher SES. SES scores were collapsed into two categories, 0-2 (low) and 3-5 (high) for each life epoch and 0-7 (low) and 8-15 (high) for cumSES.

\section{Metabolic Syndrome}

Blood pressure, triglycerides, high-density lipoprotein cholesterol (HDL-C), glucose, and waist-to-hip ratio were measured according to standard ARIC procedures (36). Participants were asked to fast twelve hours before the blood draw and fasting times were recorded. Blood was drawn from an antecubital vein of seated participants, blood was centrifuged, and frozen serum samples were shipped to central laboratories for analysis. Trained technicians measured waist and hip circumferences to the nearest centimeter at the umbilical level and maximum buttocks, respectively. The mean of the last two of three systolic and diastolic sitting blood pressure measurements obtained from a random-zero sphygmomanometer was used to calculate blood pressure.

The MetS was defined as a binary outcome at the baseline examination (1987-1989) using the Third Report of the Expert Panel on Detection, Evaluation, and Treatment of High Blood Cholesterol in Adults (ATP III) criteria (1) as the presence of three or more of the following components: elevated blood pressure [systolic blood pressure $>130$ or diastolic blood pressure $>85 \mathrm{~mm} \mathrm{Hg}$ and/or use of anti-hypertension medications (yes/no)]; elevated triglycerides $(\geq 150$ $\mathrm{mg} / \mathrm{dl}$ ); low HDL-C [men (M) $<40 \mathrm{mg} / \mathrm{dl}$, women (W) $<50 \mathrm{mg} / \mathrm{dl}$ ]; impaired fasting (fasting $>8$ hours) glucose ( $>100 \mathrm{mg} / \mathrm{dl})$; and large waist circumference $[\mathrm{M}>102 \mathrm{~cm}(>40 \mathrm{in}), \mathrm{W}>88$ $\mathrm{cm}(>35 \mathrm{in})]$.

\section{Covariates}

The baseline covariates selected for analysis were age, sex, center (Forsyth County, NC, Jackson, MS, Minneapolis, MN and Washington County, MD), self-reported race (black or white), low-density lipoprotein cholesterol (LDL-C in $\mathrm{mg} / \mathrm{dL}$ ), physical activity, smoking status and alcohol use (current, former, never). LDL cholesterol level was calculated by using the Friedewald formula (37) at the ARIC central laboratory. Physical activity was measured using the sport during leisure time activity index (range 1-5) of Baecke's questionnaire (38). 


\section{Statistical Analysis}

Analyses were performed with SAS 9.1 (SAS Institute, Inc., Cary, NC). Given that in the US socioeconomic characteristics tend to differ among black and white persons and because the prevalence of the MetS differs by race and sex, we assessed for the presence of effect modification of the SES - MetS association by race and sex using the Wald statistic $(p<0.10)$. Race and sex were significant modifiers of the SES - MetS relation, thus all further results are stratified by race and sex.

Given the high prevalence of the MetS (greater than $10 \%$ in all race sex groups), Poisson regression, implemented using generalized estimation equations, was used to assess associations between SES and MetS as it has been shown to provide more accurate estimates of PRs in such circumstances (39). To prevent underestimation of standard errors owing to overdispersion, the Pearson scale option was used (40).

Behavioral and physiological CVD risk factors (Table 1) and SES measures (Table 2) of the population were described as means and proportions stratified by MetS status, race and sex. The strength of associations between various SES measures, including childhood, early adulthood, middle adulthood, and cumulative SES and MetS (Table 3) were estimated by prevalence ratios (PR) and 95\% confidence intervals (CI). For each SES measure, two models were run: Model 1 adjusted for age and ARIC study center. Model 2 adjusted for Model 1 covariates, in addition to physical activity, cigarette smoking status and alcohol drinking status. The center and age variables were retained in the model, since they were found to be confounders of the SES-MetS relationship. Physical activity, LDL-C, smoking and alcohol use were not found to be confounders. However, since physical activity, smoking and alcohol use are regarded as strong risk factors for MetS in the literature, and did not change our point estimates, these variables remained in the model. To examine if behavioral CVD risk factors mediated the association between SES measures and the MetS, the percentage change of each SES measure was calculated by comparing PRs between Model 1 and Model 2.

\section{RESULTS}

Prevalences of the MetS were 28.5\% $(\mathrm{n}=1345)$ among white women, 39.4\% ( $\mathrm{n}=622)$ among black women, $23.6 \%(\mathrm{n}=1314)$ among white men and $28.6 \%(\mathrm{n}=253)$ among black men (Table 1). Women and men with the MetS were older and more likely to have low levels of HDL-C compared to participants without the MetS. As per the definition of the MetS, women and men with the MetS were more likely to have high blood pressure, high glucose levels, large waists, and high triglyceride levels than those without the MetS. Among both black and white participants, there were no differences in physical activity levels and smoking status by MetS. White women with the MetS were less likely to currently drink alcohol, while among black women and white and black men the prevalence of current drinkers did not vary by MetS status. Lastly, white and black women and white men with the MetS had higher values of LDL-C, while among black men no differences were observed.

White women with the MetS had lower childhood, early adulthood, middle adulthood and cumulative SES scores, and had higher proportions of low SES compared to women without the MetS (Table 2). Black women had comparable childhood SES scores by MetS, whereas black women with the MetS had lower early adulthood, middle adulthood and cumulative SES score compared to black women without the MetS. Furthermore, black women with the MetS had a higher proportion of low SES compared to black women without the MetS. Among white and black men SES measures were comparable by MetS status, except that black men with the MetS had a slightly higher mean cumSES score compared to black men without the MetS. 
Figure 1 presents the age-adjusted prevalence of the MetS by childhood, early adulthood, middle adulthood and cumulative SES scores for each race-sex group. Among women, moderate inverse gradients between SES scores and the MetS were observed. Among men, prevalences of the MetS were generally similar across levels of childhood SES, adulthood SES and cumSES scores, with the exception of a higher prevalence of the MetS among black men with low middle adulthood SES at mid-life.

Table 3 presents Model 1 and Model 2 multivariable adjusted PRs and 95\% CIs for the association between SES and the MetS, where high SES was the referent group. Among men for both Model 1 and Model 2, there were no associations between childhood SES, early adulthood SES, middle adulthood SES or cumSES and the MetS. In contrast, among women there were inverse associations between childhood, early adulthood, middle adulthood and cumulative SES and the MetS in Model 1. In Model 2, which further considered the contribution of physical activity and current smoking and drinking, there were only minimal changes in PRs (ranging from $-6 \%$ to $+4 \%$ ).

When we repeated analyses including all participants who had prevalent diabetes at baseline $(\mathrm{n}=12051)$, the associations between childhood SES, early adulthood SES, middle adulthood SES and cumSES and the MetS remained similar (data not shown).

\section{DISCUSSION}

Low childhood, early adulthood, middle adulthood and cumulative SES were all associated with the MetS in adult women, independent of age and ARIC study center. In contrast, SES was not associated with the MetS in men. This is the first study, to our knowledge, to examine the association between cumulative exposures to adverse SES across the life course and the MetS in adulthood.

Several pathways have been proposed to explain how SES at various life epochs or across life is related to disease outcomes, such as sensitive periods in childhood and the accumulation of risk throughout the life course (41). However, since the MetS is chronic in nature, the cumulative SES hypothesis seems most appropriate. The childhood sensitive period pathway supports the hypothesis that adverse experiences which occur during childhood may have longterm health effects in adulthood, wherein biological and sociological mechanisms which occur in childhood have stronger effects on adult disease than other life periods (41-43). The cumulative life course model focuses on the accumulation of risk throughout the life course on chronic disease (41). We found that the cumulative measure of life course SES showed a modestly stronger association with the MetS, compared with childhood, early adulthood and middle adulthood SES. One possible explanation is that the accumulation of adverse SES exposures beginning in childhood and continuing on throughout the life course have detrimental biological, behavioral and sociological effects that influence the development of the MetS.

Our finding that adulthood SES is associated with the MetS is consistent with previous findings (7-15,17-21,36,44). However the literature on the effect of childhood SES on the MetS is conflicting. Langenberg and colleagues (11) and Schooling and colleagues (20) found that childhood SES was associated with the MetS in adulthood, suggesting the importance of life course SES pathways, whereas Lucove and colleagues (14) and Parker and colleagues (22) found null associations when examining this relationship. All but one (14) of these studies assessing the childhood SES - MetS relation stratified by sex. Langenberg and colleagues (11) and Schooling and colleagues (20) found more consistent and stronger associations in women; no sex differences were observed by Parker and colleagues (22). 
There are numerous reasons why low childhood SES may be associated with higher risk for the MetS in adults. MetS that emerged in adults could have resulted from poor diets in childhood and its associated obesity (45). Childhood obesity has been shown to track into adulthood and may contribute to the development of the MetS (46). Other evidence suggests that low childhood SES followed by depression, hostility and poor social contacts is relevant to the development of the components of the MetS (47). Childhood macronutrient density of diets, obesity and psychosocial health were not measured in the ARIC Study, but they are potentially important mediators that deserve attention in future studies.

In our study, however, the SES - MetS associations were not explained by behavioral CVD risk factors, suggesting that other mechanisms not considered in this analysis may be involved. These findings agree with a study in China by Schooling and colleagues, who found no significant change in SES - MetS associations after adjusting for adult behavioral CVD risk factors, in addition to height (20). Our results contrast with earlier work that found that behavioral CVD risk factors more strongly attenuated SES - MetS associations when examining adolescent, early adulthood, middle adulthood and older adulthood SES (12). Low SES has also been linked with distress (48) and depression $(49,50)$. Persons with low SES may have fewer personal resources and experience more stressful life events than persons with higher SES, and as a result persons may be more vulnerable to the negative impacts of stress on health $(51,52)$.

There are several mechanisms by which SES may differentially impact the MetS in adult women and men. It has been suggested that obesity is one of the main drivers of the MetS (23). Furthermore, obesity may influence economic trajectories $(53,54)$, especially in women. Therefore, stronger SES - MetS associations in women may in part be due to a higher prevalence of central adiposity in women than in men. However, when we examined the crosssectional association between SES and large-waist in adults in a previous study (21), statistically significant inverse associations were limited to white women. When we additionally examined the relationships between SES and components of the MetS in the current study (data not shown), SES - large-waist associations were either weaker or comparable to other SES - component associations. Alternatively, it has been postulated that women with low SES experience more psychosocial disadvantage than men, because of a higher likelihood of being unemployed, a single parent and/or depressed (55), and thus they may be more at risk for the development of the MetS, due to the relationship between low SES and stress-related neuroendocrine dysfunction.

This study had several strengths. Unlike other studies, we examined the impact of cumulative SES on the MetS in adulthood, based on an array of SES measures from three life epochs. Complimenting this, we separately analyzed childhood, early adulthood and middle adulthood SES with the MetS. Lastly, our study is based on a large biracial cohort with standardized risk factor assessment of men and women from diverse communities in the US population.

LC-SES data were collected in 2001-2002, and thus participants who died, were lost to follow up or refused to participate were not included in our study. These participants were more likely to have low adult SES (data not shown), and thus our results may be biased toward the null. It is also likely that childhood SES may have been recalled with greater error than the contemporaneous SES measures, which could in part account for the weaker childhood SES - MetS associations observed. It is also possible that individuals with low adulthood SES may be more likely to recall a lower SES in childhood, thus biasing retrospectively measured childhood SES. In support of this hypothesis we found that among men, there were no associations between chronic low SES and the MetS (data not shown) and among women there were inverse associations between chronic low SES and the MetS. However, it is reassuring that the pattern of our main findings in this manuscript were consistent by race and sex with a 
previous assessment of the cross-sectional effect of SES on the MetS in adulthood in the ARIC Study, where retrospective recall bias was not an issue (21). Physical activity level, smoking and drinking status were obtained via self-report. While we adjusted for these factors in our models, inaccuracies in their measurement may have resulted in residual confounding.

Childhood diet, obesity and psychosocial measures and adult psychosocial measures were not ascertained in the ARIC baseline examination, and thus we could not evaluate their potential role. Although the life course questionnaire was pretested in all ARIC study communities, it has not been validated in different populations. It is possible that the appropriateness of the life course questionnaire may not generalize to other population groups. Lastly, Black examinees were included only in two southern US communities and likely are not representative of blacks in the US.

In conclusion, cumulative SES over the life course, as well as its components, were inversely related to the MetS in middle-aged women but not men. Efforts aimed at understanding the associations of these sex differences, and their mechanisms, may offer insight into approaches to reduce the prevalence of the MetS.

\section{Acknowledgments}

Grants: This research was supported by the National Heart, Lung and Blood Institute (NHLBI) grant No. 1R01HL080287 (K. M. R.) and 1R01HL080287-01S1 (K. M. R and K. L. C.). The ARIC Study is carried out as a collaborative study supported by contracts from the NHLBI (N01-55015, N01-55016, N01-55018, N01-55019, N01-55020, N01-55021, N01-55022, and R01-HL064142).

The authors thank the staff and participants of the ARIC study for their important contributions.

\section{List of Abbreviations and acronyms}

US

MetS

CHD

CVD

SES

HPA

ARIC

NC

MS

MN

MD

LC-SES

cumSES

HDL-C

$\mathrm{M}$

$\mathrm{W}$

LDL-C

PR
United States

metabolic syndrome

coronary heart disease

cardiovascular disease

socioeconomic status

hypothalamic-pituitary-adrenocortical

Atherosclerosis Risk in Communities Study

North Carolina

Mississippi

Minnesota

Maryland

Life Course Socioeconomic Status, Social Context and Cardiovascular Disease cumulative socioeconomic status

high-density lipoprotein cholesterol

men

women

low-density lipoprotein cholesterol

prevalence ratio 
confidence interval

\section{REFERENCES}

1. Executive Summary of The Third Report of The National Cholesterol Education Program (NCEP) Expert Panel on Detection, Evaluation, And Treatment of High Blood Cholesterol In Adults (Adult Treatment Panel III). Jama 2001;285:2486-2497. [PubMed: 11368702]

2. Lorenzo C, Williams K, Hunt KJ, Haffner SM. The National Cholesterol Education Program - Adult Treatment Panel III, International Diabetes Federation, and World Health Organization definitions of the metabolic syndrome as predictors of incident cardiovascular disease and diabetes. Diabetes Care 2007;30:8-13. [PubMed: 17192325]

3. Malik S, Wong ND, Franklin SS, Kamath TV, L'Italien GJ, Pio JR, Williams GR. Impact of the metabolic syndrome on mortality from coronary heart disease, cardiovascular disease, and all causes in United States adults. Circulation 2004;110:1245-1250. [PubMed: 15326067]

4. McNeill AM, Rosamond WD, Girman CJ, Golden SH, Schmidt MI, East HE, Ballantyne CM, Heiss G. The metabolic syndrome and 11-year risk of incident cardiovascular disease in the atherosclerosis risk in communities study. Diabetes Care 2005;28:385-390. [PubMed: 15677797]

5. McNeill AM, Rosamond WD, Girman CJ, Heiss G, Golden SH, Duncan BB, East HE, Ballantyne C. Prevalence of coronary heart disease and carotid arterial thickening in patients with the metabolic syndrome (The ARIC Study). Am J Cardiol 2004;94:1249-1254. [PubMed: 15541239]

6. Ninomiya JK, L'Italien G, Criqui MH, Whyte JL, Gamst A, Chen RS. Association of the metabolic syndrome with history of myocardial infarction and stroke in the Third National Health and Nutrition Examination Survey. Circulation 2004;109:42-46. [PubMed: 14676144]

7. Brunner EJ, Marmot MG, Nanchahal K, Shipley MJ, Stansfeld SA, Juneja M, Alberti KG. Social inequality in coronary risk: central obesity and the metabolic syndrome. Evidence from the Whitehall II study. Diabetologia 1997;40:1341-1349. [PubMed: 9389428]

8. Carnethon MR, Loria CM, Hill JO, Sidney S, Savage PJ, Liu K. Risk factors for the metabolic syndrome: the Coronary Artery Risk Development in Young Adults (CARDIA) study, 1985-2001. Diabetes Care 2004;27:2707-2715. [PubMed: 15505009]

9. Dallongeville J, Cottel D, Ferrieres J, Arveiler D, Bingham A, Ruidavets JB, Haas B, Ducimetiere P, Amouyel P. Household income is associated with the risk of metabolic syndrome in a sex-specific manner. Diabetes Care 2005;28:409-415. [PubMed: 15677801]

10. Kim MH, Kim MK, Choi BY, Shin YJ. Educational disparities in the metabolic syndrome in a rapidly changing society--the case of South Korea. Int J Epidemiol 2005;34:1266-1273. [PubMed: 16131515]

11. Langenberg C, Kuh D, Wadsworth ME, Brunner E, Hardy R. Social circumstances and education: life course origins of social inequalities in metabolic risk in a prospective national birth cohort. Am J Public Health 2006;96:2216-2221. [PubMed: 17077402]

12. Loucks EB, Magnusson KT, Cook S, Rehkopf DH, Ford ES, Berkman LF. Socioeconomic position and the metabolic syndrome in early, middle, and late life: evidence from NHANES 1999-2002. Ann Epidemiol 2007;17:782-790. [PubMed: 17697786]

13. Loucks EB, Rehkopf DH, Thurston RC, Kawachi I. Socioeconomic disparities in metabolic syndrome differ by gender: evidence from NHANES III. Ann Epidemiol 2007;17:19-26. [PubMed: 17140811]

14. Lucove JC, Kaufman JS, James SA. Association between adult and childhood socioeconomic status and prevalence of the metabolic syndrome in African Americans: the Pitt County Study. Am J Public Health 2007;97:234-236. [PubMed: 17194854]

15. Park MJ, Yun KE, Lee GE, Cho HJ, Park HS. A cross-sectional study of socioeconomic status and the metabolic syndrome in Korean adults. Ann Epidemiol 2007;17:320-326. [PubMed: 17300958]

16. Park YW, Zhu S, Palaniappan L, Heshka S, Carnethon MR, Heymsfield SB. The metabolic syndrome: prevalence and associated risk factor findings in the US population from the Third National Health and Nutrition Examination Survey, 1988-1994. Arch Intern Med 2003;163:427-436. [PubMed: 12588201] 
17. Perel P, Langenberg C, Ferrie J, Moser K, Brunner E, Marmot M. Household wealth and the metabolic syndrome in the Whitehall II study. Diabetes Care 2006;29:2694-2700. [PubMed: 17130207]

18. Salsberry PJ, Corwin E, Reagan PB. A complex web of risks for metabolic syndrome: race/ethnicity, economics, and gender. Am J Prev Med 2007;33:114-120. [PubMed: 17673098]

19. Santos AC, Ebrahim S, Barros H. Gender, socio-economic status and metabolic syndrome in middleaged and old adults. BMC Public Health 2008;8:62. [PubMed: 18282285]

20. Schooling CM, Jiang CQ, Lam TH, Zhang WS, Cheng KK, Leung GM. Life-course origins of social inequalities in metabolic risk in the population of a developing country. Am J Epidemiol 2008;167:419-428. [PubMed: 18056924]

21. Chichlowska KL, Rose KM, Diez-Roux AV, Golden SH, McNeill AM, Heiss G. Individual and Neighborhood Socioeconomic Status Characteristics and Prevalence of Metabolic Syndrome: The Atherosclerosis Risk in Communities (ARIC) Study. Psychosom Med. 2008

22. Parker L, Lamont DW, Unwin N, Pearce MS, Bennett SM, Dickinson HO, White M, Mathers JC, Alberti KG, Craft AW. A lifecourse study of risk for hyperinsulinaemia, dyslipidaemia and obesity (the central metabolic syndrome) at age 49-51 years. Diabet Med 2003;20:406-415. [PubMed: 12752491]

23. Kahn R. Metabolic syndrome: is it a syndrome? Does it matter? Circulation 2007;115:1806-1810. discussion 11. [PubMed: 17404171]

24. Meigs JB. The metabolic syndrome. Bmj 2003;327:61-62. [PubMed: 12855493]

25. Grundy SM. Metabolic syndrome: connecting and reconciling cardiovascular and diabetes worlds. J Am Coll Cardiol 2006;47:1093-1100. [PubMed: 16545636]

26. Brindley DN. Neuroendocrine regulation and obesity. Int J Obes Relat Metab Disord 1992;16:S73S79. [PubMed: 1338326]

27. Brunner E. Stress and the biology of inequality. BMJ 1997;314:1472-1476. [PubMed: 9167568]

28. Rosmond R, Bjorntorp P. The hypothalamic-pituitary-adrenal axis activity as a predictor of cardiovascular disease, type 2 diabetes and stroke. J Intern Med 2000;247:188-197. [PubMed: 10692081]

29. Barbeau EM, Krieger N, Soobader MJ. Working class matters: socioeconomic disadvantage, race/ ethnicity, gender, and smoking in NHIS 2000. Am J Public Health 2004;94:269-278. [PubMed: 14759942]

30. Mobley LR, Root ED, Finkelstein EA, Khavjou O, Farris RP, Will JC. Environment, obesity, and cardiovascular disease risk in low-income women. Am J Prev Med 2006;30:327-332. [PubMed: 16530620]

31. Krieger N, Barbeau EM, Soobader MJ. Class matters: U.S. versus U.K. measures of occupational disparities in access to health services and health status in the 2000 U.S. National Health Interview Survey. Int J Health Serv 2005;35:213-236. [PubMed: 15932004]

32. Jackson R, Chambless LE, Yang K, Byrne T, Watson R, Folsom A, Shahar E, Kalsbeek W. Differences between respondents and nonrespondents in a multicenter community-based study vary by gender ethnicity. The Atherosclerosis Risk in Communities (ARIC) Study Investigators. J Clin Epidemiol 1996;49:1441-1446. [PubMed: 8970495]

33. The Atherosclerosis Risk in Communities (ARIC) Study: design and objectives. The ARIC investigators. Am J Epidemiol 1989;129:687-702. [PubMed: 2646917]

34. Life Course Socioeconomic Status, Social Context and Cardiovascular Disease (LC-SES) Study. Manual of Procedures http://lifecourseepiinfo/lifecourse2/forms/indexhtm.

35. Carson AP, Rose KM, Catellier DJ, Kaufman JS, Wyatt SB, Diez-Roux AV, Heiss G. Cumulative socioeconomic status across the life course and subclinical atherosclerosis. Ann Epidemiol 2007;17:296-303. [PubMed: 17027292]

36. Wamala SP, Lynch J, Horsten M, Mittleman MA, Schenck-Gustafsson K, Orth-Gomer K. Education and the metabolic syndrome in women. Diabetes Care 1999;22:1999-2003. [PubMed: 10587833]

37. Friedewald WT, Levy RI, Fredrickson DS. Estimation of the concentration of low-density lipoprotein cholesterol in plasma, without use of the preparative ultracentrifuge. Clin Chem 1972;18:499-502. [PubMed: 4337382]

38. Baecke JA, Burema J, Frijters JE. A short questionnaire for the measurement of habitual physical activity in epidemiological studies. Am J Clin Nutr 1982;36:936-942. [PubMed: 7137077] 
39. McNutt LA, Wu C, Xue X, Hafner JP. Estimating the relative risk in cohort studies and clinical trials of common outcomes. Am J Epidemiol 2003;157:940-943. [PubMed: 12746247]

40. Allison, P. Logistic Regression using the SAS system. Cary, NC: SAS; 1999.

41. Kuh, D.; Ben-Schlomo, Y. A Life Course Approach to Chronic Disease Epidemiology. Oxford: Oxford University Press; 1997.

42. Ben-Shlomo Y, Kuh D. A life course approach to chronic disease epidemiology: conceptual models, empirical challenges and interdisciplinary perspectives. Int J Epidemiol 2002;31:285-293. [PubMed: 11980781]

43. Power C, Hertzman C. Social and biological pathways linking early life and adult disease. Br Med Bull 1997;53:210-221. [PubMed: 9158295]

44. Silventoinen K, Pankow J, Jousilahti P, Hu G, Tuomilehto J. Educational inequalities in the metabolic syndrome and coronary heart disease among middle-aged men and women. Int J Epidemiol 2005;34:327-334. [PubMed: 15659460]

45. Nicklas TA, Baranowski T, Cullen KW, Berenson G. Eating patterns, dietary quality and obesity. J Am Coll Nutr 2001;20:599-608. [PubMed: 11771675]

46. Sun SS, Liang R, Huang TT, Daniels SR, Arslanian S, Liu K, Grave GD, Siervogel RM. Childhood obesity predicts adult metabolic syndrome: the Fels Longitudinal Study. J Pediatr 2008;152:191200. [PubMed: 18206688]

47. Lehman BJ, Taylor SE, Kiefe CI, Seeman TE. Relation of childhood socioeconomic status and family environment to adult metabolic functioning in the CARDIA study. Psychosom Med 2005;67:846854. [PubMed: 16314588]

48. Cohen S, Doyle WJ, Baum A. Socioeconomic status is associated with stress hormones. Psychosom Med 2006;68:414-420. [PubMed: 16738073]

49. Koster A, Bosma H, Kempen GI, Penninx BW, Beekman AT, Deeg DJ, van Eijk JT. Socioeconomic differences in incident depression in older adults: the role of psychosocial factors, physical health status, and behavioral factors. J Psychosom Res 2006;61:619-627. [PubMed: 17084139]

50. Lorant V, Deliege D, Eaton W, Robert A, Philippot P, Ansseau M. Socioeconomic inequalities in depression: a meta-analysis. Am J Epidemiol 2003;157:98-112. [PubMed: 12522017]

51. Bosma H, Van Jaarsveld CH, Tuinstra J, Sanderman R, Ranchor AV, Van Eijk JT, Kempen GI. Low control beliefs, classical coronary risk factors, and socioeconomic differences in heart disease in older persons. Soc Sci Med 2005;60:737-745. [PubMed: 15571892]

52. Taylor SE, Seeman TE. Psychosocial resources and the SES-health relationship. Ann N Y Acad Sci 1999;896:210-225. [PubMed: 10681899]

53. Gortmaker SL, Must A, Perrin JM, Sobol AM, Dietz WH. Social and economic consequences of overweight in adolescence and young adulthood. N Engl J Med 1993;329:1008-1012. [PubMed: 8366901]

54. Sargent JD, Blanchflower DG. Obesity and stature in adolescence and earnings in young adulthood. Analysis of a British birth cohort. Arch Pediatr Adolesc Med 1994;148:681-687. [PubMed: 8019620]

55. Thurston RC, Kubzansky LD, Kawachi I, Berkman LF. Is the association between socioeconomic position and coronary heart disease stronger in women than in men? Am J Epidemiol 2005;162:5765. [PubMed: 15961587] 
White women $(n=4724)$

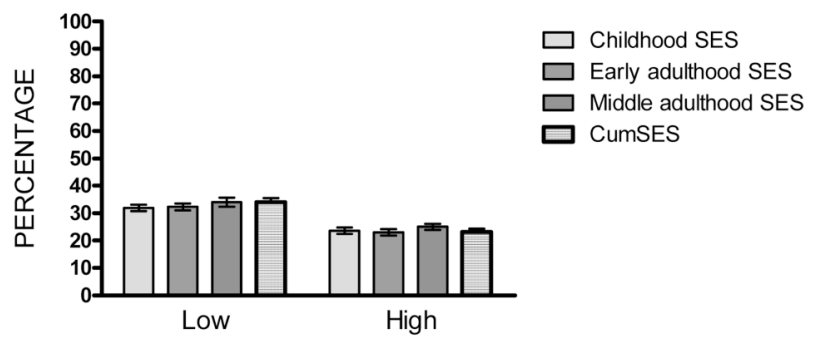

White men $(n=3812)$

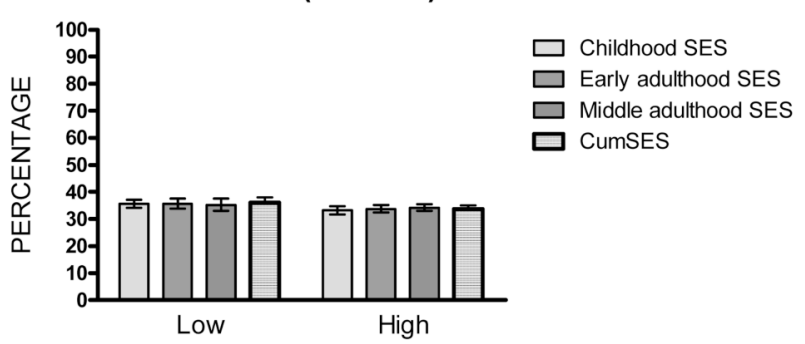

Black women ( $n=1577)$

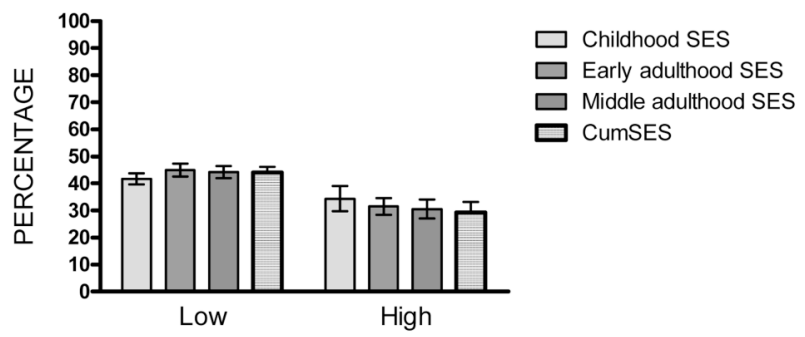

Black men $(n=884)$

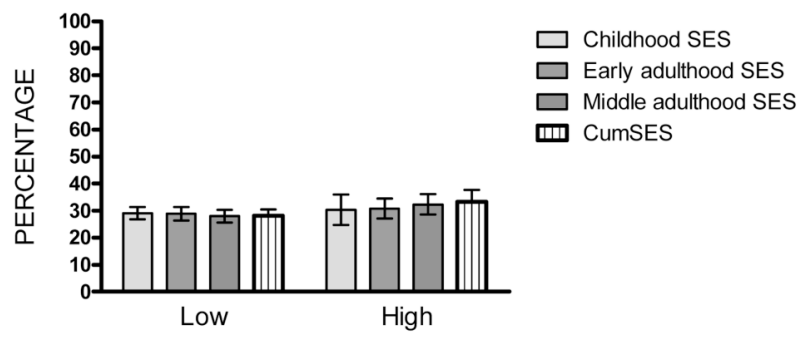

FIGURE 1.

Age-Adjusted Prevalence of the Metabolic Syndrome by Socioeconomic Status, Race and Sex, Atherosclerosis Risk in Communities Study (1987-1989)

* SES = socioeconomic status; CumSES = cumulative SES. 


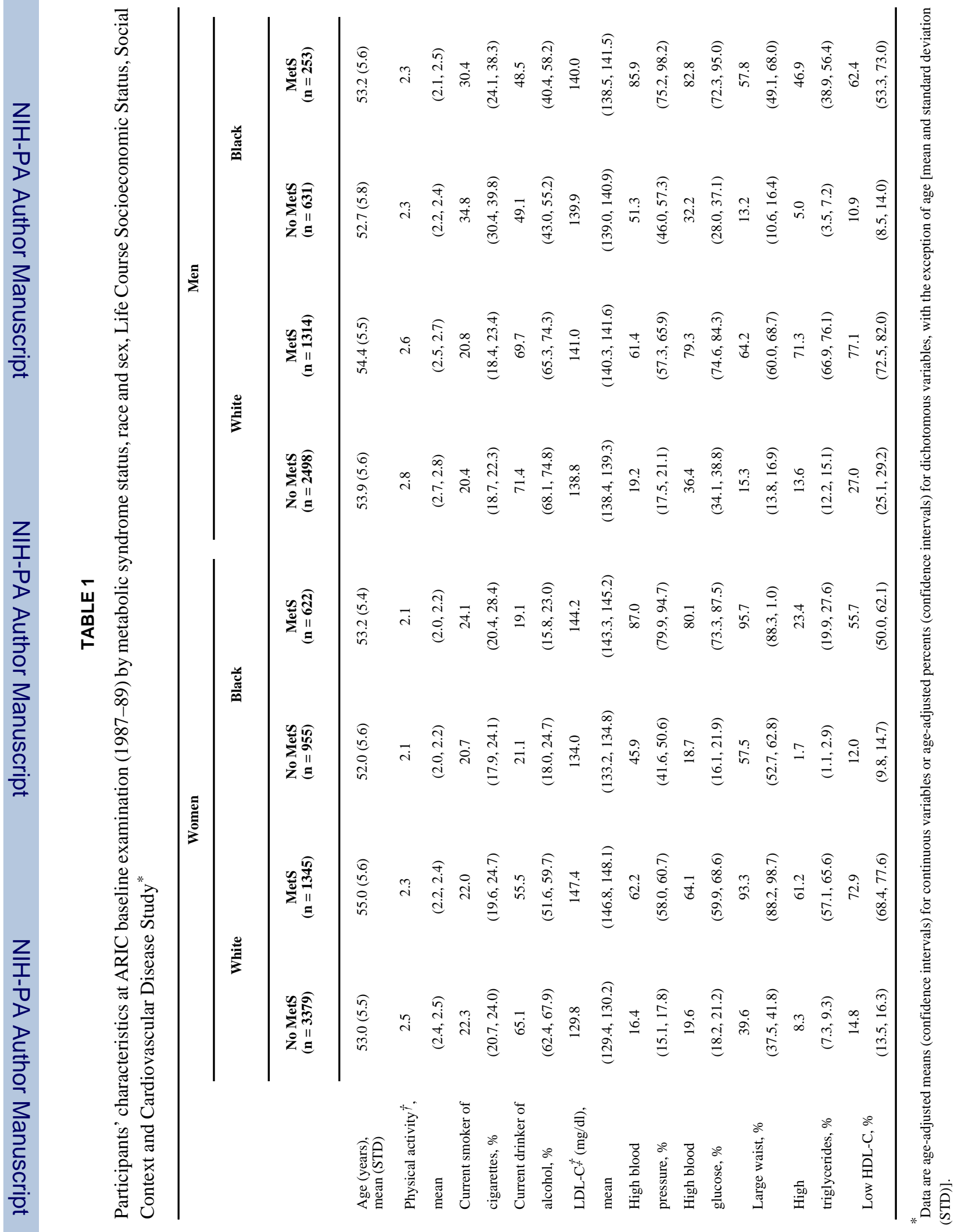




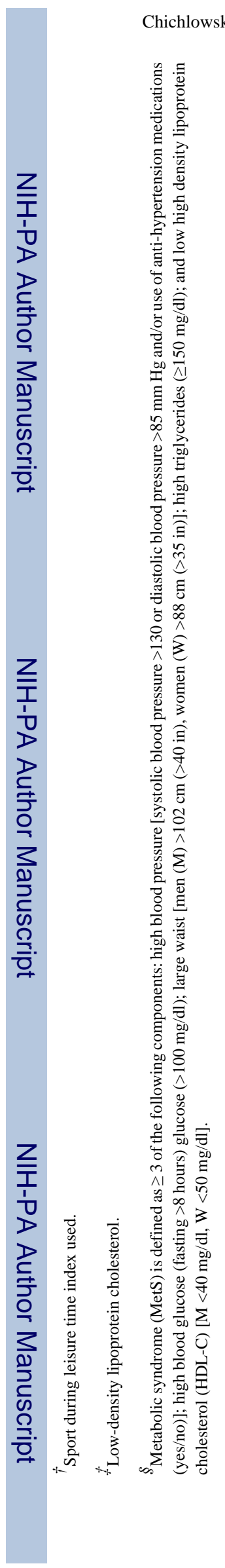

Page 13

Ann Epidemiol. Author manuscript; available in PMC 2010 December 1. 


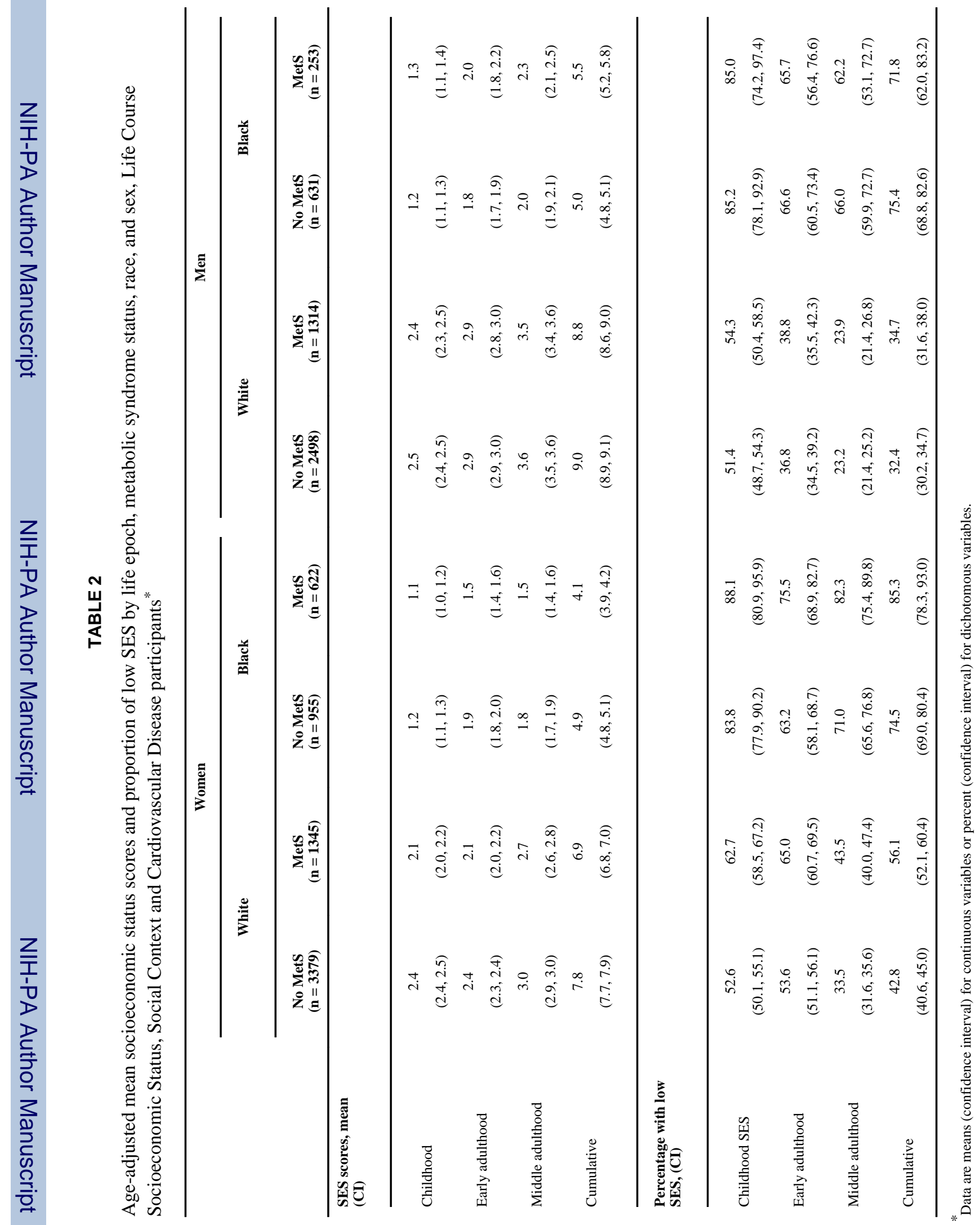




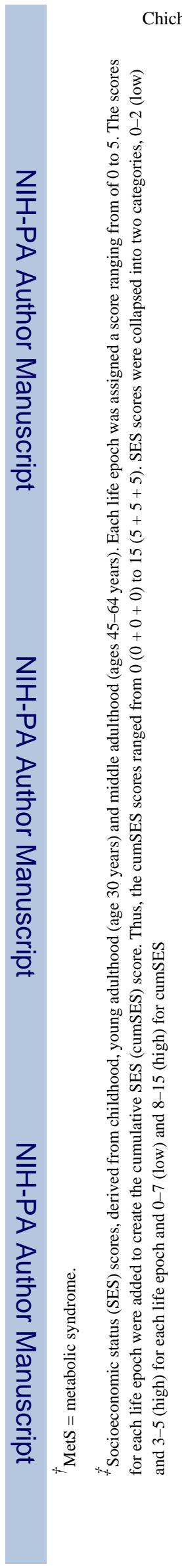

Ann Epidemiol. Author manuscript; available in PMC 2010 December 1. 


\section{TABLE 3}

Baseline (1987-89) adjusted prevalence ratios and 95\% confidence intervals of the metabolic syndrome by socioeconomic status, race, and sex, Life Course Socioeconomic Status, Social Context and Cardiovascular Disease Study*

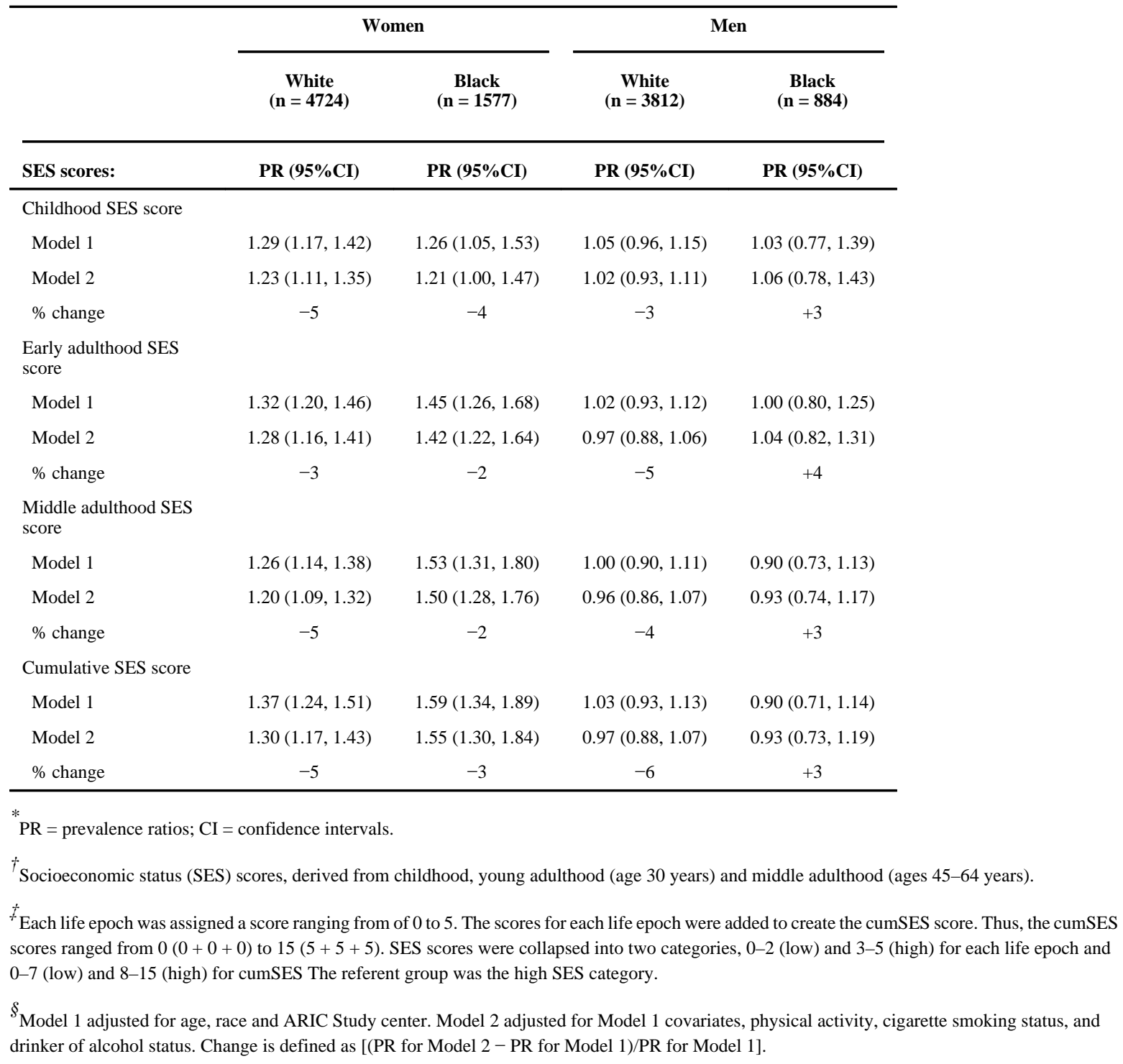

